\title{
The interdisciplinary approach of public health
}

\author{
Maike Bellmann
}

Published online: 10 May 2012

(C) Springer-Verlag 2012

The key focus of public health is to prevent disease and to promote health. Public health is not only aimed at medically undersupplied people but at all population groups. Issues such as health services research, social hygiene, prevention, environmental health, epidemiology and healthcare systems research play an important role in this area.

Under the overall heading of Public Health, which represents an interdisciplinary approach, there is a huge amount of ideas, initiatives and interventions. They offer plenty of space for science and research, whose results often form the basis for health policy requirements. Likewise, also the Journal of Public Health reflects the variety of topics dealing with communicable and non-communicable diseases, therapy strategies, healthy habitats, as well as costs in the healthcare system etc.

In this edition of the Journal of Public Health the following articles are included: Santos F. et al. give an overview on the rising cost of manual lymphatic drainage for health insurance in Germany. A Chinese research group, led by Huang Y. et al., looks at the drug varenicline in a systematic review. The long-term efficacy and safety of smoking cessation drugs are examined on the basis of Meta-analyzes of randomized controlled trials.

John Wang C. K. et al. carried out research on the topic sport and compared physical activity and sedentary behavior on the basis of model-based latent profile analysis. Alongside adequate exercise, a balanced diet is important to stay

\section{Bellmann $(\triangle)$}

Research Association Public Health Saxony and Saxony-Anhalt, Faculty of Medicine, Technische Universität Dresden, 01307 Dresden, Germany

e-mail: maike.bellmann@tu-dresden.de healthy. The food environment is linked to dietary intake and the researchers $S$. C. Lucan and N. Mitra integrated the method of GIS mapping. Agrawal P. et al. demonstrated the issue of overweight and obesity and mainly referred to the negative effects on pregnancy in India.

Another article from India, written by Mahapatro M. et al., focuses on the relationship between interpersonal violence and sexually transmitted diseases in women. In two other studies from India, bacteria that could be a high risk for human health are taken up as an issue. Samanta S. et al. carried out two cross-sectional surveys which deal with the impact of various socio-demographic influences on the parasitic infestation of the intestine and pick up on such factors as use of a sanitary latrines or access to medication. Sahu M. C. et al. approach on multi-resistances in hospitals and recorded nosocomial and community-acquired accounts of antibiotic resistance in Pseudomonas aeruginosa strains.

The article from Sun H. et al. takes up the theme of Legionella pneumophila. The authors show that L. pneumophila contaminated cooling towers contribute to high seroprevalence of antibodies. The article from Mir D. F. considered pest management and deals especially with child-care facilities and the implementation of integrated pesticide management trainings. In the following article, a specific disease is mentioned. Often herpes zoster caused great pain and led to an influence on the quality of life, says Weinke T. et al.

The research group led by Mahran D.G. et al. explored the field of women's health. The focus of the study was the prevalence of low bone-mineral density among reproductive age women in rural Upper Egypt. Finally, Ippoliti $R$. considered the costs during the production process of drugs, especially the topic "Clinical research on empirical work on the European market of human experimentation." 